\section{Contracting in mental health}

\author{
C. J. SIMPSON
}

The National Health Service (NHS) and Community Care Act 1990 introduced the UK to the purchaser/provider split (Burns \& Bhugra, 1995). This bisection of the NHS resulted in the need for contracts between the two component parts and over the past seven years contracting between purchasers and providers has evolved. Mental health contracting has followed in the footsteps of medical and surgical contracting and it is only recently that health authorities, provider units and psychiatrists have become aware of the distinctive requirements of mental health services which need to be reflected within the contracting process.

\section{PURCHASER/PROVIDER SPLIT}

Some consider it ironic that the British Government, when considering their reforms in 1990, looked to the US health care system, which itself was near breaking point and in need of reform (Butler, 1993). The need to control expenditure and link it to health needs, as well as the ideology of the free market, led to the purchaser/provider split (Klein, 1995). This has resulted in contracts between the different parts but it differs from commerce as the internal market involves one part of the NHS contracting with another (Glynn \& Murphy, 1995). The precise and detailed specification of contractual terms so that agreements about services can be explicit and specified (as opposed to implicit and general) is seen by some as one of the major advantages of this internal market.

\section{Effectiveness of the purchaser/ provider split}

There is no evidence in health care that a split between the purchasers and providers produces the desired results. The USA certainly has purchasers and providers, with the big insurance companies as the main purchasers. For those unable to buy health insurance (which includes the majority of the severely mentally ill) the government system of Medicaid is the purchaser according to the state, county or city, with different funding agencies for welfare, housing and support services (Butler, 1993).

For mental health, this makes comparisons difficult. In the USA the mental health services that function best appear to be those which have close working relationships with agencies of state, county and city to develop jointly a full range of services from federal funding. These services are therefore managed, rather than being left to develop on a free-market basis, and specific contracts are made for different types of services (Butler, 1993). This coordinated and managed system uses the contracting process and appears to work, but it is not aided by the split between different purchasers and providers.

\section{EVOLUTION IN CONTRACTING IN THE UK}

After the NHS and Community Care Act 1990 , the roles of the health authorities have been to act as both the contracting purchasers of services from providers, and the commissioners determining the health needs that inform the purchasing decisions.

\section{Fundholding}

The general practitioner fundholders (GPFHs) complicated the system. They have been able to buy services, but not necessarily be involved in assessing the health needs of the area. The proportion of GPFH practices has increased over the years, with the result that in some areas the majority of patients have their services bought by them. In addition, the services available for purchase by the GPFHs has been extended and currently includes all out-patient community mental health work, but excludes in-patient mental health work. As mental health services have increasingly concentrated on community mental health teams, until recently the GPFHs have been able to buy only parts of these teams, resulting in services from different team members being purchased from different bodies. This process is currently being extended into total purchasing and commissioning groups which, together with the Labour Government's proposed dissolution of GPFHs, may bring the role of the assessment of health needs back to the purchasing bodies themselves.

\section{Activity as currency}

Until the past few years, mental health services have been part of general contracts between purchasers and providers. The contracts have contained the same methodology with an increasing emphasis on cost being related to activity. There are four major flaws with this process. First, in mental health the prediction of outcomes from a diagnosis is notoriously unreliable. Therefore, it is difficult to cost accurately the treatment of a person with, for instance, schizophrenia. This can be contrasted with the relative ease of costing the treatment of, for instance, an inguinal hernia repair. Second, commissioning agencies have been keen to develop the health promotion role of provider mental health services. This includes providing a liaison service to the primary health care team through telephone contact, meetings and educational activities. These cannot be costed through the amount of referrals. Indeed, as the majority of the mentally ill are treated in primary care (Goldberg \& Huxley, 1978), it is argued that secondary services should reinforce this so as to prevent the need for referral. Third, the use of contacts as a measure is misleading. The numbers of patients being seen is of little relevance, whereas smaller case loads of patients with specific illnesses and seen for longer is more in keeping with good practice (Stein \& Test, 1980). Fourth, a system whereby a mental health service increases its income by admitting patients shows a perverse incentive against the principles of care in the community. These four problems are essentially related to the use of activity as a currency within the contracts.

\section{Role of strategies}

As part of the planning role of health authorities, it is expected that they all have 
mental health strategies (NHS Executive, 1996). This has only become the case over the past few years, and in 199533 of the 111 health authorities in England had still not developed a mental health strategy (NHS Executive, 1996). In 199612 of the 80 respondents from 100 health authorities in England had still not developed a mental health strategy (Simpson, 1997). As a strategy should determine the contents of contracts, this is a low figure. However, health authorities are addressing this issue. As awareness has increased about the different contents of the contracts and the need to allocate specific money to mental health services, the need for separate contracts has become apparent (Farrar, 1996).

\section{Medical involvement}

Another area of development over the past few years has been that of clinical involvement in the contracting process. Absence of clinician involvement led the NHS Executive to recommend some ways of doing this (NHS Executive, 1995), and by the 1996/7 contract in England, 55\% of health authorities had a consultant psychiatrist involved in the meetings (Simpson, 1997). This may largely reflect the involvement of medical directors of mental health trusts. Indeed, the involvement in contract meetings is time-consuming and often awkward for psychiatrists but their presence challenges the managers to ensure the contracts are clinically relevant. This can result in better service organisation and effectiveness.

\section{Health Advisory Service}

These problems with mental health commissioning were highlighted in a Health Advisory Service survey of commissioning, which looked at the documentation for mental health services produced by health authorities in England and Wales for 1993/ 4 and 1994/5 (Cumella et al, 1996). In addition, this study looked in more detail at a random sample of 20 health authorities and analysed the commissioning documentation for mental health services in London. This showed the poor development of mental health strategies, that commissioning was reactive rather than planned and that different kinds of services were being purchased from GPFHs and from health authorities. Partly as a result of this study there is now a move towards separate mental health contracts linked to the health authority strategies (Farrar, 1996).

\section{MENTAL HEALTH CONTRACTS IN 1996/7}

A recent study on mental health contracts in England in 1996/7 reveals the current situation (Simpson, 1997). Although 82\% of respondents reported having a discrete contract for mental health, this did not necessarily include a discrete amount of funding for this contract. Health authorities often, therefore, provide separate contracts for service specification and quality standards, but include the funding within the whole contract with the provider. Although the majority of contracts are block contracts, purchasers continue to request large amounts of information on activity as a basis for the contract, but report it as being of little use. Quality measures are seen as being more useful and almost all health authorities use the Care Programme Approach (CPA), supervision register and supervised discharge as a form of quality standard. Twenty-one per cent of purchasers do not do quality visits with the providers.

Although the majority (85\%) now have a strategy, most do not use the contracts to reflect the targets in the strategy. In addition, the majority of health authorities do not have an agreed purchasing strategy with the GPFHs, which must cause major problems in the coordination of services.

This study has shown how little mental health knowledge there is at the health authority level, with poor development of mental health contracts in comparison with other contracts. There is much unhappiness about the use of activity as a currency within the contracts, but little use of other currencies other than quality standards. In terms of a purchasing strategy there is poor coordination between the health authorities and GPFHs.

\section{CONTRACTING IN THE FUTURE}

The poor coordination between health authorities and GPFHs may be resolved by the development of commissioning groups whereby GPFHs, GP non-fundholders and health authorities purchase services together. Having psychiatrists actually involved in the negotiations helps the focus on clinical problems. Regular meetings between consultant psychiatrists and managers from mental health services and the commissioning groups to monitor the contracts can also improve the dialogue between purchasers and providers (Gallagher, 1996). Our patients require our medical input into this process if they are to receive the most clinically appropriate services.

The major challenge for the future, however, is the replacement of activity as a currency, with the development of alternatives that are meaningful and useful. Some health authorities have used epidemiological data such as the MINI (Glover et al, 1997) programme to help determine the funding arrangements. The use of 'healthcare resource groups' in mental health has not yet been of great value in predicting resource use in different settings (NHS Executive, 1997a). The continuing development of such information, together with the piloting of a new minimum data set for mental health, is evidence of some interest in developing data collection for comprehensive mental health services. The use of integrated care pathways or care packages as a basis for contracting may have advantages over the simple activity measures currently used. Certain packages of care with agreed quality measures could then be bought, for example people receiving electroconvulsive therapy with certain documentation and information provided. Another approach could be the use of quality standards associated with certain programmes, as in how many people on the supervision register have been seen within the past month. These ideas are all currently being explored by the Contract Currency Project in South London (M. Elphick \& R. Carthew, personal communication, 1997). One approach being explored is the combination of condition groups (such as diagnosis or health care resource groups) and care groups (such as treatment settings or interventions) along different axes resulting in a matrix. This may provide more meaningful information than at present, but still is essentially measuring in units of activity with its inherent drawbacks.

The idea of purchasing health and social care jointly has recently been raised as a possibility (NHS Executive, 1997b) in order to coordinate these services better. This is important as it has been recognised that inquiries into tragedies often highlight gaps between health care and social services provision (Zito Trust, 1995).

While purchasers consider these ideas, the two most likely currencies for the future are outcome and quality measures. 
Purchasers are already considering using the Health of the Nation Outcome Scale (HoNOS) in contracts so that eventually providers can be asked to improve the outcome of those referred by a certain percentage on the HoNOS. Quality measures are currently used in terms of the CPA, supervision register and supervised discharge, and the proportion of people seen with severe mental illness is also likely to be used more over the next few years.

Although most observers are unhappy with current contract arrangements, it is often the providers who, forced to provide useless information to their purchasers, are exploring alternatives. Psychiatrists are notably absent in this process. At a recent meeting of those in the UK interested in developing new currencies, only one health authority was represented and only two psychiatrists were present.

Contracting in mental health requires a different format to contracting in other parts of medicine. It is poorly developed at present and needs the involvement of psychiatrists to ensure that it reflects the needs of mental health services. There is general dissatisfaction with the current arrangements from health authorities and little coordination between the health authorities and GPFHs. Contracting currencies are being developed which may prove far more meaningful than the current large-scale collection of unusable mental health information by the NHS.

C. J. SIMPSOM, FRCPsych, Department of Mental Health, Friarage Hospital, Northallerton, North Yorkshire DL6 IJG

(First received II March 1997, revised 31 July 1997, accepted 26 August 1997)

\section{ACKNOWLEDGEMENT}

This paper is based on a dissertation for the Postgraduate Diploma in Leading and Managing in the Health Service at the University of York.

\section{REFERENCES}

Burns, A. \& Bhugra, D. (1995) History and structure of the National Health Service. In Manogement for Psychiatrists (2nd edn) (eds D. Bhugra \& A. Burns), pp. 3-17. London: Gaskell.

Butler, T. (1993) Changing Mental Health Services: The Politics \& Policy. London: Chapman \& Hall.

Cumella, S., Williams, R. \& Sang, R. (1996) How mental health services are commissioned. In Commissioning Mental Health Services (eds G. Thornicroft \& G. Strathdee), pp. 59-69. London: Department of Health.

Farrar, M. (1996) Monitor quality. In Commissioning Mental Health Services (eds G. Thornicroft \& G. Strathdee), pp. 293-307. London: Department of Health.

Gallagher, S. (1996) Implementing the core service components: commissioning and contracting. In Commissioning Mental Health Services (eds G. Thornicroft \& G. Strathdee). London: Department of Health.

Glover, G. R., Robin, E., Emami, J., et al (1997) The needs index for mental health care. Social Psychiatry and Psychiatric Epidemiology, in press.
Glynn, J. \& Murphy, M. (1995) Contracting, quality and marketing in the NHS. In Management for Psychiatrists (2nd edn) (eds D. Bhugra \& A. Burns), pp. 85-99. London: Gaskell.

Goldberg, D. \& Huxley, P. (1978) Mental Illness in the Community. London: Tavistock.

Klein, R. (1995) The New Politics of the NHS (3rd edn) London: Longman.

NHS Executive (1995) Clinical Involvement in Controcting. A Handbook of Good Practice. Leeds: NHS Executive.

- (1996) Review of the Purchasing of Mental Health Services by Health Authorities in England. Leeds: NHS Executive.

- (1997a) Mental Health Report: Cosemix Outcome Resources Needs. The National Cosemix Office. London: NHS Executive.

- (1997b) Developing Portnerships in Mentol Health Green Poper. London: Department of Health.

Simpson, C. J. (1997) Paper chase. Heolth Services journal, 107, 32-33.

Stein, L. Test, M. (1980) Alternative to mental hospital treatment, I. Conceptual model, treatment programme and clinical evaluation. Archives of Generol Psychiatry, 37, 392-397.

Zito Trust (1995) Learning the Lessons: Mental Health Enquiry Reports published in England and Woles between 1969-1994 and their Recommendations for Improving Proctice. London: Zito Trust. 